\title{
ARTIKELEN
}

\section{De Unierechtelijke status van de Caribische Koninkrijksdelen}

\author{
Mr. G.D. Rekwest*
}

\section{Inleiding}

Tijdens een conferentie over de relatie tussen de Europese Unie (EU) en de Caribische delen van het Koninkrijk op 4 juli 2019 bij de Erasmus Universiteit Rotterdam sprak Ernst Hirsch Ballin ${ }^{1}$ over de mogelijkheden voor de Caribische delen van het Koninkrijk om een vernieuwende richting in te slaan en gebruik te maken van meer ruimte voor variëteit. ${ }^{2}$ Hirsch Ballin pleitte voor een herijking van de relatie tussen de Caribische delen van het Koninkrijk en de EU. De discussie over de Unierechtelijke status van de Caribische Koninkrijksdelen is niet nieuw. In september 2017 werden de verschillen van de status van Landen en Gebieden Overzee (LGO) van het Nederlandse Sint Maarten en de status van Ultraperifeer Gebied (UPG) van het Franse Saint Martin pijnlijk duidelijk toen het eiland getroffen werd door orkaan Irma. Alleen het Franse Saint Martin kon een beroep doen op het Solidariteitsfonds van de Europese Unie (SFEU) en het Nederlandse deel van het eiland niet. In aanloop naar de ontmanteling van de voormalige Nederlandse Antillen in 2010, is in 2008 in opdracht van het Ministerie van Binnenlandse Zaken en Koninkrijksrelaties (BZK) onderzoek gedaan naar de juridische ${ }^{3}$ en economische ${ }^{4}$ implicaties van de status van UPG voor de Caribische rijksdelen. In 2015 heeft de commissie-Spies in haar evaluatierapport aandacht besteed aan de Unierechtelijke status van de BES-eilanden. ${ }^{5}$ Uit dit rapport blijkt dat aan een statuswijziging van LGO naar UPG veel haken en ogen zitten.

Stel dat Nederland, de EU en de Caribische rijksdelen een nauwere band tussen de eilanden met de EU wensen, welke ontwikkelingen spelen dan een rol bij de keuze voor de LGOstatus dan wel wijziging naar de UPG-status?

In deze bijdrage worden de mogelijkheden voor een statuswijziging verkend. In de loop van paragraaf 2 wordt ingegaan op de mogelijk gewijzigde positie van de LGO in relatie tot

* Mr. G.D. Rekwest is promovenda fiscaal recht bij de University of Curaçao en de Erasmus Universiteit Rotterdam.

1 Hoogleraar aan Tilburg University en hoogleraar Rechten van de Mens aan de Universiteit van Amsterdam, president van het Asser Instituut voor Internationaal en Europees Recht.

2 E. Hirsch Ballin, 'Ruimte voor variëteit', Antilliaans Dagblad 31 juli 2019.

3 H.E. Bröring e.a. (red.), Schurende rechtsordes: over juridische implicaties van de UPG-status voor de eilandgebieden van de Nederlandse Antillen en Aruba, Rijksuniversiteit Groningen 2008 (hierna: Brőring e.a. 2008).

4 SEOR, Economische gevolgen van de status van Ultraperifeer Gebied voor de Nederlandse Antillen en Aruba, Erasmus Universiteit Rotterdam, juni 2008.

5 J.W.E. Spies e.a. (red.), Vijf jaar verbonden: Bonaire, Sint Eustatius, Saba en Europees Nederland, Den Haag oktober 2015. 
de EU na het aflopen van het Verdrag van Cotonou in februari 2020 waardoor geen nieuw Europees Ontwikkelingsfonds (EOF) wordt gecreëerd. In paragraaf 3 zullen de gevolgen en procedure van een wijziging in de UPG-status worden besproken. Eerst wordt in paragraaf 2 ingegaan op de huidige, complexe relatie van de LGO met de EU. Hoewel in deze bijdrage enige aandacht wordt besteed aan de fiscaliteit, ligt daar niet de nadruk op.

\section{De status van Landen en Gebieden Overzee (LGO)}

\subsection{Inleiding}

Denemarken, Frankrijk, het Verenigd Koninkrijk (VK) en Nederland hebben op het moment van schrijven tezamen 25 LGO. ${ }^{6}$ De LGO hebben een speciale relatie met EUlidstaten; zo horen ze niet alleen grondwettelijk bij de moeder-lidstaat, maar de onderdanen van de LGO hebben daarnaast ook de nationaliteit van de moeder-lidstaat. De LGOstatus is sinds de oprichting van de Europese Economische Gemeenschap (EEG) in 1957, mede op aandringen van Frankrijk gecreëerd om de (voormalige) koloniën te betrekken bij de gemeenschappelijke markt. ${ }^{7}$ Dit was nodig omdat zij economisch afhankelijk zijn van het moederland. Er werd aansluiting gezocht bij het Franse systeem. Frankrijk maakte namelijk al onderscheid tussen enerzijds de TOM (territoire d'outre-mer) waarmee Frankrijk een lossere band had en anderzijds de DOM (departement d'outre-mer) waar Frankrijk nauw mee verbonden is. Het onderscheid betrof de overzeese gebieden die onder het nationale recht van het moederland meer autonomie genoten en in beginsel geheel buiten de interne markt bleven (de huidige LGO-status) en de overzeese gebiedsdelen die juist volledig deel uitmaakten van de lidstaat (de huidige UPG-status).

Aangezien de LGO geen onderdeel uitmaken van de interne markt, zijn ook de EU-verkeersvrijheden in principe niet van toepassing op de relatie tussen de LGO en de EU. Alleen voor het vrij verkeer van goederen geldt een beperkte werking. Uit artikel 200 van het Verdrag betreffende de werking van de Europese Unie (VWEU) blijkt dat over goederen van oorsprong uit de LGO bij invoer in de EU geen invoerrechten betaald hoeven te worden. Overigens mogen de LGO wel invoerrechten heffen over goederen afkomstig uit de EU. Of het vrije kapitaalverkeer tussen de LGO en de lidstaat van toepassing is, is sinds lange tijd onduidelijk. Dit heeft vooral te maken met de complexe en ondefinieerbare status van de LGO in relatie tot de EU. In paragraaf 2.4 wordt daar nader op ingegaan.

\subsection{Het huidige LGO-Besluit}

In het vierde deel van het VWEU zijn de lidstaten overeengekomen om de niet-Europese landen en gebieden, welke bijzondere betrekkingen onderhouden met Denemarken, Frankrijk, Nederland en het VK, te associëren met de EU. Dit wordt de associatieregeling genoemd. In de lijst die als bijlage gevoegd is bij het VWEU is opgenomen welke gebieden

6 Anguilla, Aruba, Bermuda, Bonaire, Brits Antarctisch Territorium, Brits Indische Oceaanterritorium, Britse Maagdeneilanden, Curaçao, Falklandeilanden, Franse Zuidelijke en Antarctische Gebieden, Frans-Polynesië, Groenland, Kaaimaneilanden, Montserrat, Nieuw-Caledonië, Pitcairneilanden, Saba, Saint-Barthélemy, Saint-Pierre en Miquelon, Sint Eustatius, Sint Maarten, Sint-Helena, Ascension en Tristan da Cunha, Turksen Caicoseilanden, Wallis en Futuna, Zuid-Georgia en de Zuidelijke Sandwicheilanden.

7 Bröring e.a. 2008, p. 56. 
dit zijn. Volgens artikel 198 VWEU, dat specifiek ziet op de LGO van de EU-lidstaten, is het doel van de associatie om de economische en sociale ontwikkeling van de LGO te bevorderen en nauwe economische betrekkingen tussen de LGO en de EU in haar geheel tot stand te brengen. Dit is uitgewerkt in het LGO-Besluit. ${ }^{8}$ Op 1 januari 2014 is het huidige LGO-Besluit in werking getreden. ${ }^{9}$ In de preambule van het besluit is de verschuiving van de relatie tussen de LGO en de lidstaat van de klassieke benadering in de vorm van ontwikkelingssamenwerking naar een wederkerig partnerschap ter ondersteuning van de duurzame ontwikkeling van de LGO expliciet verwoord. Duidelijk is dat naar meer gelijkwaardigheid tussen de partijen wordt gestreefd. In dit kader maakte Nederland tijdens de onderhandelingen over het nieuwe LGO-Besluit bezwaar tegen het voorstel om de verantwoordelijkheid voor administratieve fouten van de LGO bij de lidstaat te leggen. ${ }^{10}$ Nederland heeft benadrukt alleen verantwoordelijkheid te kunnen dragen voor administratieve fouten van de BES-eilanden, maar niet van de autonome landen in het Koninkrijk. Het standpunt van het land Nederland op dit punt is begrijpelijk. Echter, niet het land Nederland, maar het Koninkrijk der Nederlanden is lidstaat. Dat betekent dat tegen het Koninkrijk een inbreukprocedure kan worden gestart als het EU-recht in de LGO niet wordt nagestreefd. Een dergelijke procedure heeft overigens al eens plaatsgevonden jegens de Republiek Frankrijk vanwege het niet nakomen van verplichtingen uit het LGO-Besluit. ${ }^{11}$

Het LGO-Besluit van 2014 richt zich op drie pijlers: (1) versterking van het concurrentievermogen, (2) vergroting van de veerkracht en vermindering van de kwetsbaarheid en (3) stimulering van samenwerking en integratie tussen de LGO en andere partners in de naburige regio's. ${ }^{12} \mathrm{Zo}$ is het mogelijk om nauwer samen te werken met de Caribische handelsorganisatie CARICOM. ${ }^{13}$ Dit is belangrijk aangezien de eilanden veel handel drijven in het Caribische gebied. In het besluit van 2014 is er ook aandacht voor de rol van de LGO als hubs of excellentiecentra, bijvoorbeeld op het gebied van duurzame energie. Toerisme, een belangrijke sector voor de eilanden, is in het besluit expliciet benoemd als samenwerkingsgebied tussen LGO en EU. Een ander aspect is dat het voor de LGO onder het LGOBesluit 2014 eenvoudiger is om toegang te krijgen tot de Europese fondsen omdat ondersteuning bij de aanvraag wordt geboden. Hoewel het besluit van 2014 een verbetering is ten opzichte van het voormalige besluit, is nog niet op alle terreinen sprake van een gelijkwaardige positie voor de LGO in relatie tot de lidstaten. Zo is het nog steeds de lidstaat die uiteindelijk de status van de LGO bepaalt en niet de LGO. Daarnaast fungeert de lidstaat nog altijd als aanspreekpunt voor de EU. ${ }^{14}$

8 Besluit 2001/822/EEG van de Raad van 27 november 2001 betreffende de associatie van de LGO met de Europese Gemeenschap (PbEU 2001, L 314).

9 Besluit 2013/755/EU van de Raad van 25 november 2013 (PbEU 2013, L 344).

10 Brief van de Minister van Buitenlandse Zaken van 29 oktober 2013, MINBUZA 2013.295850.

11 HvJ EEG 12 december 1990, C-263/88, ECLI:EU:C:1990:454.

$12 \operatorname{COM}(2012) 362$.

13 Deze afkorting staat voor Caribbean Community and Common Market.

14 F. Goudappel, 'Het nieuwe LGO-besluit: een herziene relatie tussen de EU en de Overzeese Gebieden', Ars Aequi 2014, afl. 6, p. 458. 


\subsection{Het nieuwe LGO-Besluit 2021}

Op 14 juni 2018 is door de Europese Commissie een voorstel voor een nieuw LGO-Besluit uitgevaardigd. ${ }^{15}$ Dit voorstel, dat van toepassing moet worden op 1 januari 2021, maakt onderdeel uit van het Meerjarig Financieel Kader (MFK) voor 2021-2027 en zal van toepassing zijn op de dertien LGO die na Brexit een relatie hebben met Denemarken, Frankrijk en Nederland. In het voorstel worden het LGO-Besluit en het Groenlandbesluit samengevoegd om meer eenheid van beleid te creëren. Alle LGO vallen alsdan onder dezelfde financieringsbron. Daarnaast is de samenvoeging ingegeven door de aanstaande Brexit waardoor de speciale regeling van het vierde deel van het VWEU niet langer van toepassing zal zijn op de twaalf Britse LGO. Het nieuwe LGO-Besluit houdt vast aan de bestaande drie pijlers: politieke zaken, handel en samenwerking. In het nieuwe besluit is veel aandacht voor duurzame ontwikkeling en klimaat. Daarnaast wordt de samenwerking tussen LGO, UPG, ACS-landen (Afrika, Caraiben, Stille Oceaan-landen) en andere landen aangemoedigd. Ten aanzien van de beschikbare financiële middelen voor de LGO blijkt uit het MFK dat voor de periode 2021-2027 225 miljoen euro beschikbaar wordt gesteld voor de LGO van Nederland en Frankrijk. Het beschikbare budget is in absolute termen lager dan onder het elfde EOF, maar het budget hoeft niet gedeeld te worden met de Britse LGO. In paragraaf 3 zal hier nader op ingegaan worden. Nederland staat overigens positief ten opzichte van het voorstel, waarbij sprake is van meer zichtbaarheid van de LGO, vereenvoudiging van de procedures en meer mogelijkheden voor regionale samenwerking. ${ }^{16}$ Nederland heeft evenwel vragen gesteld ten aanzien van de hulp bij toekomstige natuurrampen, indachtig de ervaringen van de orkanen Irma en Maria in 2017.

\subsection{Wat is de positie van de LGO in relatie tot de EU?}

De positie van de LGO in relatie tot de EU is al jaren ongrijpbaar. Zijn de LGO derde landen, een EU-associatie of zijn ze een onderdeel van een lidstaat? Het feit dat delen van het EU-verdragsregime op de relatie tussen de LGO en de EU van toepassing is, lijkt een kwalificatie als derde landen uit te sluiten. ${ }^{17}$ De LGO maken in beginsel en onder bijzondere voorwaarden beperkt onderdeel uit van de communautaire orde. Echter, de verkeersvrijheden zijn in principe op hen niet van toepassing. Alleen het vrije kapitaalverkeer is op niet-EU-landen, de zogenoemde derde landen, van toepassing. ${ }^{18}$ De vraag komt op of de LGO voor toepassing van het vrije kapitaalverkeer als derde landen moeten worden aangemerkt. Alsdan zijn belemmeringen van het vrije kapitaalverkeer niet toegestaan. Uit de hierna te behandelen rechtspraak van het Hof van Justitie van de Europese Unie (HvJ EU) lijkt een onderscheid tussen de relatie van een lidstaat met de eigen LGO, bijvoorbeeld Nederland en Curaçao, en die van de lidstaat met de LGO van een andere lidstaat, zoals bijvoorbeeld Nederland en de Britse Maagdeneilanden, relevant voor beantwoording van de vraag of het vrije kapitaalverkeer van toepassing is op de LGO. Een indicatie voor de complexiteit van de materie is de omvang van de conclusies van de advocaat-

$\operatorname{COM}(2018) 461$.

Brief van de Minister van Buitenlandse Zaken van 20 juli 2018, nr. 2670.

Art. 199 lid 1 en 5 VWEU jo. art. 200 lid 1 en 2 VWEU.

Art. 63 VWEU. 
generaal (A-G) van zowel de Hoge Raad als het HvJ EU bij de zaak Prunus Sarl (Prunus) ${ }^{19}$ en de gevoegde zaken X BV en TBG Limited $(X / T B G) .{ }^{20}$

\subsubsection{Prunus-zaak}

In de zaak Prunus had de Franse rechter prejudiciële vragen gesteld over de Unierechtelijke status van de LGO van het VK, de Britse Maagdeneilanden (BVI), ten opzichte van lidstaat Frankrijk. De BVI staan in de lijst met alle LGO van bijlage II bij het VWEU. In geding was of een Franse heffing van 3\% over onroerend goed dat gehouden werd door niet-ingezeten vennootschappen van de EU een vorm van discriminatie was. Deze heffing gold namelijk niet voor binnenlandse en EU-ingezeten vennootschappen. De vraag was of de LGO onder de reikwijdte van vrijheid van kapitaalverkeer valt. Artikel 63 VWEU verbiedt 'alle beperkingen van het kapitaalverkeer tussen lidstaten onderling en tussen lidstaten en derde landen'. Het HvJ EU overwoog dat in het VWEU de LGO niet uitdrukkelijk is gelijkgesteld met een lidstaat. Bovendien is in het VWEU niets geregeld over kapitaalverkeer tussen lidstaat en LGO. Als gevolg hiervan dienden volgens het HvJ EU de LGO voor de vrijheid van kapitaalverkeer als derde landen te worden aangemerkt. Het HvJ EU oordeelde dat artikel 63 VWEU een onbeperkte territoriale werkingssfeer heeft en dat daarom aangenomen moet worden dat dit artikel ook van toepassing is op het kapitaalverkeer naar en uit LGO. Kortom: de BVI zijn als LGO van een andere lidstaat ‘derde landen'.

Deze uitspraak van HvJ EU is opvallend omdat volgens de letterlijke tekst van de considerans van het LGO-Besluit 'de LGO geen derde landen zijn'. Bij een eerste oogopslag wekt het besluit de indruk dat geen onderscheid wordt gemaakt tussen een LGO van een andere lidstaat en de eigen LGO: de LGO zijn geen derde landen. Echter, uit de zaak Prunus en het hierna te behandelen arrest X/TBG lijkt het HvJ EU wel een dergelijk onderscheid te maken. Hoe het ook zij, het HvJ EU besliste anders: de BVI zijn derde landen waardoor artikel 63 VWEU van toepassing is. Als gevolg hiervan was de fiscale belemmering van 3\% Franse heffing niet toegestaan.

Had het HvJ EU de letterlijke tekst van de considerans van het LGO-Besluit gevolgd, namelijk dat de LGO geen 'derde landen' zijn, dan zou een merkwaardige situatie zijn ontstaan als vastgehouden wordt aan toepassing van het VWEU. Het kapitaalverkeer tussen de lidstaat en de LGO zou niet vrij zijn, terwijl dat wel het geval is voor 'derde landen', die geen LGO zijn. Hoewel de uiteindelijke conclusie van het HvJ EU juist is, is het nog maar de vraag of dat ook geldt voor de route die het HvJ EU bewandelt.

\subsubsection{X/TBG}

In de gevoegde zaken X BV en TBG Limited (X/TBG) worden op 23 december 2011 prejudiciële vragen voorgelegd over de Unierechtelijke status van de LGO. In deze zaak ging het niet om de LGO van een andere lidstaat, zoals dat in de Prunus-zaak het geval was geweest, maar de eigen LGO. De zaak betreft een Nederlandse dochtermaatschappij die een dividenduitkering deed aan de Antilliaanse moedermaatschappij. De dochtermaatschappij was op basis van (het toenmalige) artikel 11 lid 3 Belastingregeling voor het Koninkrijk 
(BRK) gehouden 8,3\% dividendbelasting in te houden. In geschil was of de inhouding van dividendbelasting een belemmerende maatregel was die in strijd is met de in het EU-Verdrag gewaarborgde verkeersvrijheden, in casu het kapitaalverkeer. De bronheffing van 8,3\% gold namelijk niet voor binnenlandse en EU-gerechtigden. De vraag is of hier sprake is van een zuiver interne situatie aangezien het de eigen LGO betrof. A-G Jääskinen verwijst eerst naar het Prunus-arrest waarin is bepaald dat de LGO in relatie met een lidstaat waarmee het niet verbonden is, als 'derde landen' kwalificeren voor toepassing van het VWEU. Volgens de A-G is geen sprake van een interne situatie en is het LGO-Besluit van toepassing.

Opvallend is dat HvJ EU de vraag over de verhouding tussen de lidstaat en de eigen LGO niet beantwoordt. Het HvJ EU overweegt dat sprake is van een bijzondere associatieregeling voor deel IV van het VWEU: het LGO-Besluit. Aangezien er een bijzondere regeling is, betekent dit volgens het HvJ EU dat de algemene bepalingen van VWEU niet op de LGO van toepassing zijn. Immers, in deel IV VWEU zijn alleen regelingen ten aanzien van het vrije verkeer van goederen, vrije verkeer van werknemers en vrije verkeer van vestiging opgenomen. Het vrije verkeer van kapitaal staat er niet tussen. Om te bepalen of een beperking voor het verkeer van kapitaal tussen een lidstaat en de LGO toegestaan is, dient volgens het HvJ EU het LGO-Besluit te worden geraadpleegd. Het besluit is ten slotte een uitwerking van deel IV VWEU. De toetsing vindt plaats aan artikel 47 LGO-Besluit (thans art. 59). Dit artikel bepaalt dat geen beperkingen mogen worden opgelegd aan dividenduitkeringen tussen de lidstaat en de LGO. Hierop maakt artikel 55 LGO-Besluit (thans art. 66) een uitzondering voor maatregelen die bedoeld zijn om belastingontduiking te bestrijden. Volgens het HvJ EU moet de bestrijding wel daadwerkelijk en evenredig worden nagestreefd. Of dat zo is, laat het HvJ EU aan de Hoge Raad over. De uitspraak van het HvJ EU is op dit punt opmerkelijk. De voorwaarde van een daadwerkelijk streven duidt namelijk op de geschiktheidstoets van de 'rule of reason-test' zoals door het HvJ EU doorgaans wordt toepast in zijn beslisschema bij toetsing van verdragsvrijheden van het VWEU. Als dat zo is, dan zou de verwachting zijn dat ook een proportionaliteitstoets plaats moet vinden. In plaats daarvan hanteert het HvJ EU echter een evenredigheidstoets op het LGO-Besluit. Wat daarvan zij, de prejudiciële vraag of artikel 63 VWEU van toepassing is in de relatie van LGO met de eigen lidstaat heeft het HvJ EU in deze zaak vooralsnog niet expliciet beantwoord.

Op 6 februari 2015 heeft de Hoge Raad arrest gewezen in deze zaak. ${ }^{21}$ De Hoge Raad oordeelt dat het ontdoen van het imago van belastingparadijs en het handhaven van de bestaande effectieve belastingdruk op deelnemingsdividenden daadwerkelijk en evenredig wordt nagestreefd met de belastingmaatregel.

$\mathrm{Nu}$ het HvJ EU de vraag over de toepassing van artikel 63 VWEU uitdrukkelijk niet beantwoordt, laat het arrest nog wel enige vragen open. Volgt uit het arrest X/TBG dat het LGOBesluit uitsluitend de relatie tussen de lidstaat en zijn eigen LGO regardeert? Betekent dit dat alleen in die relatie de LGO niet als derde landen worden aangemerkt? Kan het zijn dat in de relatie tussen de lidstaat en de LGO van een andere lidstaat de LGO wel als derde 
landen worden aangemerkt? Alsdan is niet het LGO-Besluit van toepassing is, maar artikel 63 VWEU. Alhoewel het HvJ EU zich niet expliciet uitlaat over de vraag of in de Prunus-zaak een onjuiste weg is bewandeld, lijkt ook ruimte te bestaan om aan te nemen dat het HvJ EU in deze herkansing impliciet alsnog de juiste route bewandelt. Het is ook goed verdedigbaar om te stellen dat het LGO-Besluit betrekking heeft op de relatie tussen de lidstaten en de LGO, ongeacht of het de eigen LGO betreft of andermans LGO. Hoe het ook zij, de betekenis van deze uitspraken voor de toekomstige rechtsontwikkeling en praktijk blijft op dit punt vooralsnog onduidelijk.

\section{UPG-status}

\subsection{Inleiding}

Een alternatief voor de LGO-status is de status van UPG. UPG's maken in beginsel integraal deel uit van de EU en het geheel van EU-verdragen, -verordeningen en -richtlijnen, inclusief de jurisprudentie van het HvJ EU - ook wel het EU-acquis genoemd - is volledig van toepassing. Uitzonderingen - zogeheten derogaties - op de verplichting om het EU-acquis over te nemen zijn echter mogelijk, gezien de bijzondere kenmerken van de UPG's: het insulaire karakter, de grote afstand tot het moederland, de kleine oppervlakte, het moeilijke klimaat, en de specifieke economische en sociale situatie. ${ }^{22}$ Op dit moment zijn er negen UPG's. Lidstaat Frankrijk heeft er zes (Martinique, Mayotte, Guadeloupe, Frans Guiana, Reunion en Saint-Martin), Portugal heeft er twee (Madeira, de Azoren) en Spanje heeft er één: de Canarische eilanden. Met een UPG-status vallen deze eilanden onder het EU-handelsregime. UPG's kunnen daarnaast aanspraak maken op Europese fondsen, zoals het SFEU, voorheen Structuurfondsen genoemd. In oktober 2017 heeft de Europese Commissie in een persbericht de nieuwe strategie met betrekking tot de relatie tussen de EU en de UPG's bekendgemaakt. ${ }^{23}$ Uit het persbericht blijkt dat de UPG's om een aantal redenen interessant zijn voor de EU. Ten eerste gaat het om gebieden die in vergelijking met de EU bijzondere kenmerken hebben zoals het insulaire karakter, de grote afstand tot het moederland, de kleine oppervlakte, het moeilijke klimaat, de specifieke economische situatie waardoor ze vaak afhankelijk zijn van een beperkt aantal lokale producten of natuurlijke hulpbronnen. Deze kenmerken belemmeren de eilanden in hun ontwikkeling. Voor de EU zijn deze eilanden strategisch juist waardevol door hun geografische ligging waardoor ze als uitvalbasis richting Zuid-Amerika kunnen dienen. Aanwezigheid in de 'West' betekent ook handel, investeringen en internationale samenwerking in het Caribisch gebied. Een andere reden die in het persbericht genoemd wordt, is dat deze eilanden een ecologische rijkdom hebben waardoor ze veel mogelijkheden voor onderzoek bieden.

\subsection{Statuswijziging}

Op basis van artikel 355 lid 6 VWEU is statuswijziging van LGO naar UPG (en omgekeerd) mogelijk. Sinds het Verdrag van Lissabon hoeft voor een statuswijziging het VWEU niet gewijzigd te worden. Artikel 355 lid 6 VWEU luidt als volgt:

23 Europese Commissie (2017), Press release, 24 oktober 2017, IP/17/3585, MEMO/17/3884. 
'De Europese Raad kan op initiatief van de betrokken lidstaat een besluit vaststellen tot wijziging van de status ten aanzien van de Unie van een Deens, Frans of Nederlands land of gebied als bedoeld in de leden 1 en 2. De Europese Raad besluit met eenparigheid van stemmen, na raadpleging van de Commissie.'

Deze wijzigingsprocedure geldt niet voor het VK. Bovendien ligt het initiatief tot statuswijziging bij de lidstaat en niet bij de LGO. Uit de bewoordingen van het artikel blijkt niet dat de wil van de bevolking van de gebiedsdelen een rol speelt bij de statuswijziging. Staatsrechtelijk klopt dit wel, de EU-bevoegdheden liggen nu eenmaal alleen op het niveau van de lidstaten. De Europese Raad heeft de volksraadpleging op het Franse eiland Mayotte overigens wel expliciet meegenomen bij diens besluit tot statuswijziging in UPG. ${ }^{24}$ Ook het Nederlandse kabinet heeft met betrekking tot de Caribische Koninkrijksdelen aangegeven dat de eilanden eerst zelf een keuze dienen te maken. ${ }^{25}$ Maar ook dan is het formeel nog zo dat het Koninkrijk uiteindelijk beslist. Een van de recente Unierechtelijke statuswijzigingen betreft St. Barths, een eiland dat voornamelijk op toerisme is gericht en dat in 2012 zijn UPG-status heeft gewijzigd in een LGO-status. Een van de voornaamste reden voor St. Barths om van status te wijzigen is dat het eiland moeite had om te voldoen aan het EU-recht. ${ }^{26}$

\subsubsection{De ontwikkelingen rondom LGO-status}

\subsubsection{Financiering}

Het jaar 2020 zal, zoals eerder is aangegeven, een belangrijk omslagpunt voor de positie van de LGO vormen. Dit heeft vooral te maken met de financieringsmogelijkheden die vanaf 2020 vormgegeven worden door het zogeheten Meerjarig Financieel Kader (MFK). Op dit moment komen de LGO volgens artikel 77 LGO-Besluit in aanmerking voor financiering uit het elfde EOF. Een deel van dit fonds is beschikbaar om de regionale samenwerking en integratie te bevorderen en voor financiering van humanitaire en spoedeisende calamiteiten. ${ }^{27}$ De financiering uit het EOF hangt echter nauw samen met de afspraken die de lidstaten en de ACS-landen voor de periode 2014-2020 hebben gemaakt in een partnerschapsovereenkomst, ook wel het Verdrag van Cotonou genoemd. ${ }^{28}$ Door het aflopen van het Verdrag van Cotonou in februari 2020 zal geen nieuw EOF worden gecreëerd. Het EOF zal worden vervangen door een nieuw systeem dat voor alle LGO geldt en dat onderdeel uitmaakt van het MFK.

\subsubsection{Brexit}

Een andere ontwikkeling die van grote invloed is op de LGO is de aanstaande Brexit. Britse LGO zullen hun LGO-status verliezen. In het Caribisch gebied zijn dat Bermuda, de Turksen Caicoseilanden, Anguila, Montserrat, de Kaaimaneilanden en de BVI. In een brief hebben de House of Lords in 2017 aan de Britse regering vragen gesteld over de positie van de

Besluit 2012/419/EU.

Brief van de Minister van BZK van 19 mei 2017, DGAN/17069821.

Besluit 2010/718/EU.

Verordening (EG) 215/2008.

Partnerschapsovereenkomst 2000/483/EG (PbEU 2000, L 317). 
Britse LGO na de Brexit. ${ }^{29}$ De Britse LGO maken zich vooral zorgen over de impact die de Brexit zal hebben voor hun economie, handel en financiële dienstensector. Zij zien echter ook de noodzaak in om in de toekomst meer samen te werken met omringende gebieden, zoals de Caribische LGO. Uit de reactie van de Brexit-minister David Davis op de brief van de House of Lords blijkt dat de positie van de Britse LGO niet prominent op de agenda van de Britse regering staat. ${ }^{30}$ Het ligt in de lijn der verwachting dat de positie van de Caribische LGO na een Brexit enigszins verzwakt zal zijn. Enerzijds door het wegvallen van de Britse LGO waardoor het aantal LGO de facto gehalveerd is, anderzijds vanwege de kritische houding die met name Oost-Europese lidstaten innemen ten aanzien van LGO-financiering.

\subsection{Wat willen de EU, Nederland en de eilanden?}

De vraag doet zich voor of de EU, Nederland en de Caribische Koninkrijksdelen een statuswijziging willen. Het Koninkrijk is nooit voorstander geweest om een UPG-status voor de eilanden aan te vragen. In een reactie op het eerder uitgebrachte SEOR-rapport benadrukte de Minister van Buitenlandse Zaken dat de huidige LGO-status een uitstekende toegang tot de Europese markt biedt. ${ }^{31}$ Bovendien hebben de Caribische Koninkrijksdelen, volgens de minister, ook na het SEOR-rapport niet besloten een statuswijziging in UPG in gang te zetten. Op Curaçao en Sint Maarten lijkt de Unierechtelijke status van de eilanden geen prangende kwestie. De BES-eilanden hebben als bijzondere gemeente van Nederland in principe voor een nauwere aansluiting tot de EU gekozen. In de LGO/UPG-discussie neemt Aruba een bijzondere positie in. In 2003 heeft het wetenschappelijk instituut FESCA van de Algemene Volkspartij (AVP) een rapport uitgebracht naar aanleiding van een studiereis naar Madeira en de Canarische eilanden, om de UPG-status als optie te bestuderen. ${ }^{32}$ Uit het rapport blijkt dat 'bij een aansluiting van Aruba bij de "ultraperifere club" een gemeenschappelijk optreden en belangenverdediging kan ontstaan'. Volgens het rapport zal dit ook de bestaande UPG's ten goede komen aangezien de overzeese gebieden met dezelfde problemen te kampen hebben en hierin samen kunnen optrekken richting de EU. Inmiddels lijkt de wens voor een UPG-status voor Aruba enigszins getemperd. De huidige minister-president van Aruba, mevrouw Evelyn Wever-Croes, heeft vooralsnog ten aanzien van de Unierechtelijke status van Aruba en een eventuele statuswijziging geen formeel standpunt ingenomen. Een standpunt van de EU ten aanzien van een statuswijziging van de Caribische LGO in UPG is voor zover kan worden nagegaan, niet formeel bekend. Het ligt in de lijn der verwachting dat gezien de kleinschaligheid van de eilanden de EU geen grote bezwaren zal hebben voor een wijziging in UPG-status.

29 Brief 13 september 2017, House of Lords, European Union Committee.

30 Brief 19 februari 2018, Rt Hon David Davis MP, Department for Exiting the European Union.

31 Brief van de Minister van Buitenlandse Zaken van 5 maart 2013, MINBUZA-2013.120058.

32 FESCA, Fact-finding mission Madeira en Canarische eilanden, Studie naar de praktische werking van de Ultraperifere status binnen de Europese Unie, Aruba 2003. 


\section{Conclusie}

In deze bijdrage is aandacht besteed aan de discussie over de huidige Unierechtelijke status van de Caribische Koninkrijksdelen als LGO. Daarbij zijn de mogelijkheden van een statuswijziging in UPG verkend. Uit de verkenning blijkt dat de positie van de LGO door de aanstaande Brexit allerminst zeker is. Enerzijds kan het vertrek van het VK uit de EU tot nieuwe samenwerkingen leiden tussen de Britse LGO in het Caribisch gebied met de Nederlandse LGO. Anderzijds zal de positie van de achterblijvende LGO minder stevig zijn. Het nieuwe LGO-Besluit 2021 zal tot een betere regionale samenwerking tussen de LGO kunnen leiden en ook de toegang tot de financieringsmogelijkheden voor projecten wordt vergroot. Het valt echter nog te bezien hoe daar concreet invulling aan wordt gegeven. Het UPG-alternatief lijkt aantrekkelijk, vooral door de ruimere toegang tot de EUfondsen. Maar daarbij wordt opgemerkt dat het daadwerkelijk benutten van deze EU-fondsen niet vanzelfsprekend is. Gevolg van een wijziging in UPG-status is wel de overname van het gehele EU-acquis. De statuswijziging van St. Barths in een LGO-status vanwege de problemen die het eiland had om te voldoen aan het EU-recht dient in dit kader nader onderzocht te worden. Het is lastig te voorspellen hoe de EU zal staan tegenover een statuswijziging van de eilanden in UPG. Gezien de kleinschaligheid van de eilanden lijkt het niet waarschijnlijk dat de EU afwijzend zal zijn. Hoe het ook zij, de eilanden hoeven bij een herijking van de relatie met de EU zich geenszins te laten beperken tot de twee smaken die in 1957 ontwikkeld zijn. Het zal interessant zijn als de eilanden nader onderzoek doen naar alle mogelijke relaties die zij met de EU kunnen aangaan. De aanstaande Brexit, het aflopen van het Verdrag van Cotonou in februari 2020 en het nog in te voeren LGO-Besluit 2021 geven daartoe alle aanleiding. De bal ligt hiermee met name bij de eilanden. 